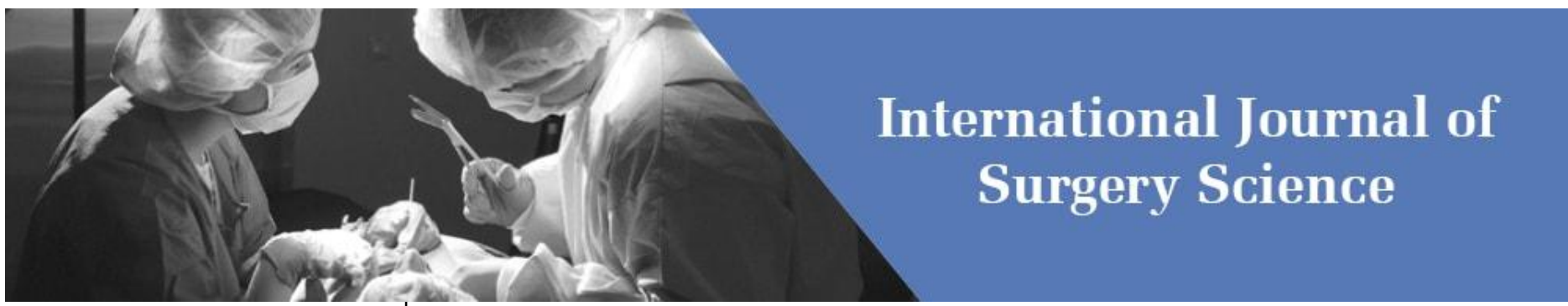

E-ISSN: 2616-3470

P-ISSN: 2616-3462

(C) Surgery Science

www.surgeryscience.com

2020; 4(2): 299-302

Received: 18-02-2020

Accepted: 21-03-2020

Dr. Ketan Vagholkar

Professor, Department of Surgery

D.Y. Patil University School of

Medicine, Navi Mumbai,

Maharashtra, India

Corresponding Author:

Dr. Ketan Vagholkar

Professor, Department of Surgery

D.Y. Patil University School of

Medicine, Navi Mumbai,

Maharashtra, India

\section{Acute cholecystitis: Severity assessment and management}

\section{Dr. Ketan Vagholkar}

DOI: https://doi.org/10.33545/surgery.2020.v4.i2e.433

Abstract

Acute cholecystitis is one of the commonest biliary tract emergency. Early diagnosis and prompt treatment is essential to reduce the morbidity and mortality associated with the disease. Assessment of the severity of the disease is essential to develop a safe therapeutic plan for the patient. The Tokyo guidelines (TG 18/TG 13) provides a lucid system for grading the severity of acute cholecystitis. Supportive care, antibiotic therapy followed by early laparoscopic cholecystectomy is the mainstay of treatment. Fitness to undergo surgery is determined by the Charlson Comorbidity Index and the American College of Anaesthesiologist's physical status examination. Those unfit for surgery are best treated by early biliary drainage followed by delayed cholecystectomy. The incidence of iatrogenic bile duct injury is high in severe cases. A low threshold for conversion to open cholecystectomy is essential in such cases to prevent iatrogenic biliovascular injuries. A holistic clinical approach comprising of establishing the diagnosis, grading the severity of acute cholecystitis, assessment of fitness to undergo surgery, administration of supportive care and antibiotics followed by early cholecystectomy constitutes a safe surgical approach to acute cholecystitis.

\section{Keywords: Acute Cholecystitis Tokyo Guidelines Cholecystectomy}

\section{Introduction}

Inflammation of the gall bladder is termed as cholecystitis. It is usually associated with gallstones in $90 \%$ of cases. However it may be acalculous in $10 \%$ of cases ${ }^{[1]}$. Acute cholecystitis is one of the common surgical emergencies. Prompt diagnosis, assessment of severity and commencement of appropriate treatment is essential to prevent morbidity and mortality. The etiopathogenesis, diagnostic challenges, severity assessment and various surgical options are discussed in the paper.

\section{Etiopathogenesis}

Acute calculous cholecystitis constitutes $90 \%$ of cases. The remaining $10 \%$ are acalculous in nature. Risk factors for calculous cholecystitis include advanced age, female sex, obesity, rapid weight loss, ethnicity, drugs and pregnancy.

Biliary stasis without gallstones is the main risk factor for acalculous cholecystitis. A multitude of conditions are associated with longstanding biliary stasis. These include debilitating medical illnesses, major surgery, severe trauma, sepsis, long term TPN and prolonged fasting. Other causes include cardiac events, sickle cell disease, salmonella infection, diabetes, and cytomegalovirus and microsporidosis infection in AIDS patients ${ }^{[2]}$.

Obstruction of the cystic duct by a stone is the inciting event in calculous cholecystitis. This leads to distension of the gall bladder thereby compromising the blood and lymphatic drainage of the gall bladder. It also causes mucosal ischaemia and necrosis. Superadded infection hastens the chain of inflammatory events. This can lead to empyema of the gall bladder ${ }^{[2]}$.

In acalculous cholecystitis there is long standing biliary stasis. This leads to accumulation of highly concentrated bile. Absence of CCK stimulation due to prolonged fasting leads to more stagnation of concentrated bile which initiates the inflammatory process accompanied by infection ${ }^{[3]}$.

In both scenarios endotoxins are formed by the infecting organisms. These endotoxins cause necrosis, haemorrhage, fibrin deposition, mucosal loss and loss of gall bladder contractility in response to CCK. This worsens the stasis ${ }^{[3]}$. 
Emphysematous cholecystitis is a complex variant. It is seen in $4 \%$ of all cases and in $25 \%$ of aclaculous cholecystitis patients. It has a strong male preponderance especially in male diabetic patients. The gall bladder wall has gas in it. The causative organisms are E Coli, Cl Perfringens and Klebsiella species. The perforation rate is $15 \%{ }^{[4]}$.

Histopathological findings in acute cholecystitis are typical [4]. These include

1. Oedema and venous congestion

2. Features of acute cholecystitis superimposed on features of chronic cholecystitis

3. Fibrosis

4. Flattening of the mucosa

5. Chronic inflammatory cells

6. Mucosal herniation due to increased hydrostatic pressure called as Rokitansky Aschoff sinuses seen in 56\% of cases

7. Focal necrosis

8. With neutrophilic infiltration

9. Gangrenous changes with perforation

10. Occasionally a silent malignancy.

\section{Clinical Features:}

The commonest presentation is acute upper abdominal pain. The pain initially is epigastric in location but latter localizes to the right hypochondrium. The nature of pain is colicky to start with but subsequently becomes constant in nature. It is associated with nausea and vomiting. Patient may also be febrile. The pain in acute cholecystitis is severe and will last for more than 6 hours while pain of biliary colic is intermittent in nature ${ }^{[5]}$

In acalculous cholecystitis the patient is severely sick. There is no preceding history of biliary colic. Pain is acute in onset and severe. It is associated with fever and systemic sepsis. Gall stones are absent.

General examination will reveal fever and tachycardia. $15 \%$ of patients will be icteric. Physical examination will reveal tenderness or rebound tenderness in the right hypochondrium. Murphy's sign will be present. Fullness will be felt in the right. hypochodrium. In severe cases guarding or rigidity may be present ${ }^{[5]}$.

However significant variations may be encountered in elderly patients and children. In elderly patients especially in diabetics the symptoms are vague with absence of typical history of symptoms and physical findings. Pain and fever may be absent. The only sign observed could be tenderness. Physical signs may not correlate to the rapidly developing inflammatory process. In children classical features will not be seen. Children suffering from sickle cell disease, haemolytic conditions, congenital biliary anomalies and prolonged TPN can develop acute cholecystitis. Therefore a high index of suspicion is necessary in evaluating abdominal pain in such children.

Patients with acute cholecystitis could also have a component of intestinal obstruction. This is due to erosion of a large stone from the gall bladder into the adjacent duodenum. The stone then passes down and could get stuck either at the duodenojejunal junction or the ileocecal junction and manifest as acute intestinal obstruction.

A patient with severe bacterial proliferation superimposed on an inflamed and obstructed gall bladder could develop an empyema of the gall bladder. Such patients can present with severe systemic signs of sepsis. Similarly the presentation could be very deceptive in diabetic patients ${ }^{[6]}$.

\section{Investigations}

Haematological investigations play a major supportive role in the diagnosis and severity assessment. Neutrophilic leucocytosis is a common finding. Raised ALT and AST are seen. The total bilirubin and alkaline phosphatase may show a transient rise during the acute phase. But persistently high levels of total bilirubin and alkaline phosphatase are seen in CBD obstruction due to a stone. Amylase levels will be high in acute cholecystitis. However a raised lipase level is seen in concomitant pancreatitis. Urine examination will help to rule out urinary tract pathology. A urinary pregnancy test is mandatory to rule out pregnant state.

Radiological investigations are the mainstay of diagnosis.

An abdominal plain $\mathrm{x}$ ray will reveal radiopaque gall stone in $15 \%$ of cases. Gas shadows limited to the gall bladder region could be suggestive of emphysematous cholecystitis. Diffuse calcification in porcelain gall bladder can also be diagnosed. A plain $\mathrm{x}$ ray of the abdomen also enables one to rule out renal calculi and obstruction.

USG is a very important investigation ${ }^{[7]}$. It has a sensitivity of $90-95 \%$ and specificity of $75-80 \%$ in diagnosing gall stones greater than $2 \mathrm{~mm}$ in diameter. For better yield it is best performed following a fast of 8 hours. This enables the gall bladder to get distended by bile for better visualisation of gall stones. Findings in acute cholecystitis are

1. Presence of gall stones in the gall bladder.

2. Gall bladder wall thickening greater than $4 \mathrm{~mm}$.

3. Pericholecystic collection.

4. Radiologic Murphy's sign.

5. Presence of sludge.

Contrast enhanced USG using agent perflubutane helps in diagnosing gangrenous cholecystitis ${ }^{[7]}$.

Disadvantages of USG are

1. Operator and patient dependent.

2. Unable to visualise the cystic duct.

3. Decreased sensitivity for CBD stones.

4. Inaccurate findings in concomitant acute pancreatitis.

\section{CT and MRI.}

Sensitivity and specificity in diagnosing acute cholecystitis is greater than $95 \%$. Its biggest advantage is that it is non-invasive but has the disadvantage of not having any therapeutic utility.

Findings in acute cholecystitis are

1. Gall stones.

2. Gall bladder wall thickening greater than $4 \mathrm{~mm}$.

3. Subserosal edema.

4. Intramural gas.

5. Sloughed mucosa.

MRI has an additional advantage of being able to differentiate between acute and chronic cholecystitis.

\section{Hepatobiliary Scintigraphy (HBS).}

HBS has sensitivity of $90-100 \%$ and specificity of $85-95 \%$ in diagnosing acute cholecystitis. [8, 9] A normal scan will show filling of the gall bladder, CBD and small bowel within 30-45 minutes. If the gall bladder is not visualized then morphine should be administered to increase the accuracy by increasing the resistance to flow through the sphincter of Oddi resulting in filling of the gall bladder if the cystic duct is patent. Morphine reduces the false positive rate in critically ill patients. In acute cholecystitis the gall bladder cannot be visualized.

\section{ERCP.}

If there are features suggestive of CBD stones then an ERCP is 
indicated. The main advantage is that it is both diagnostic as well as therapeutic. The only disadvantage is the chance of developing pancreatitis ${ }^{[10]}$.

\section{Diagnostic criteria for acute cholecystitis}

The Tokyo guidelines (TG 18/ TG 13) has laid down diagnostic criteria for acute cholecystitis. [8]

A. Local signs of inflammation

1. Murphy's sign

2. Right upper quadrant pain, tenderness or mass.

B. Systemic signs of inflammation

1. Fever

2. Elevated CRP

3. Raised WBC count

C. Imaging findings

Characteristic of acute cholecystitis.

Suspected cholecystitis - one item from A + one item from B.

Definitive diagnosis - one item from $\mathrm{A}+$ one item from $\mathrm{B}+\mathrm{C}$.

Once the diagnosis is established the severity of cholecystitis needs to be quantified. This will not only provide a road map but also enable the attending surgeon to formulate a treatment plan.

\section{Assessment of severity of acute cholecystitis}

The severity of acute cholecystitis is crucial as it has a significant impact on the chances of iatrogenic bile duct injury during the operation of cholecystectomy. Tokyo grade II/III have almost 8 times the risk of iatrogenic bile duct injury. Hence it is important to assess the severity of the disease. The Tokyo guidelines (TG 18/TG13) provide a comprehensive system for grading the severity in acute cholecystitis based on clinical, haematological and radiological criteria ${ }^{[8,9]}$.

\section{Severe acute cholecystitis (Grade III)}

Associated with dysfunction of any of the following organ systems.

1. CVS dysfunction: Hypotension requiring dopamine administration at the rate of 5 micrograms $/ \mathrm{kg} / \mathrm{min}$ or more.

2. Neurological dysfunction: decreased level of consciousness.

3. Respiratory dysfunction: $\mathrm{PaO} 2$ / FiO2 ratio of less than 300 .

4. Renal dysfunction: Oliguria, creatinine greater than 2 $\mathrm{mg} / \mathrm{dl}$.

5. Hepatic dysfunction: PT/ INR greater than 1.5

6. Haematological dysfunction: platelet count less than 1, 00, $000 / \mathrm{mm}^{3}$.

\section{Moderate acute cholecystitis (Grade II)}

Associated with any one of the following criteria.

1. Elevated WBC count greater than $18,000 / \mathrm{mm}^{3}$.

2. Palpable tender mass in the right upper abdominal quadrant.

3. Duration of complaints more than 72 hours.

4. Marked inflammation. (gangrenous cholecystitis, pericholecystic collection, hepatic abscess, biliary peritonitis, emphysematous cholecystitis)

\section{Mild acute cholecystitis (Grade I)}

Does not meet the criteria for grade III and grade II acute cholecystitis. Grade I is defined as acute cholecystitis in a healthy patient with no organ dysfunction and mild inflammatory changes in the gall bladder region.

The severity of acute cholecystitis has then to be correlated to risk assessment in each patient. This is done by using the Charlson Comorbidity Index (CCI) and American Society of
Anaesthesiologist's Physical Status classification system (ASAPS). ${ }^{[1,12]}$ (Table $1 \& 2$ ).

Table 1: Charlson Comorbidity Index

\begin{tabular}{|c|c|c|}
\hline \multicolumn{2}{|c|}{ Assigned weights for disease } & Condition \\
\hline 1 & $\begin{array}{r}\text { Myocardial infarct } \\
\text { disease, dementia, chr } \\
\text { tissue diseases, pepti } \\
\text { uncompli }\end{array}$ & $\begin{array}{l}\mathrm{D} \text {, cerebrovascular } \\
\text { ry disease, connective } \\
\text { e, mild liver disease, } \\
\text { mellitus. }\end{array}$ \\
\hline 2 & $\begin{array}{r}\text { Hemiplegia, moderat } \\
\text { diabetes mellitus } \\
\text { tumour, }\end{array}$ & $\begin{array}{l}\text { ronic kidney disease, } \\
\text { damage, any solid } \\
\text { nphoma. }\end{array}$ \\
\hline 3 & Moderate & er disease \\
\hline 6 & Metastat & Ir, AIDS \\
\hline
\end{tabular}

A score of 0 shows no co morbidities were diagnosed.

As the score rises, the predicted mortality rate rises.

Table 2: American Society of Anaesthesiologists Physical Status Classification System. (ASA-PS)

\begin{tabular}{|c|c|}
\hline $\begin{array}{c}\text { ASA } \\
\text { grade }\end{array}$ & Description \\
\hline I & Normal healthy patient \\
\hline II & Patient with mild systemic disease \\
\hline III & Patient with severe systemic disease \\
\hline IV & $\begin{array}{c}\text { Patient with severe systemic disease that is a constant threat } \\
\text { to life }\end{array}$ \\
\hline V & $\begin{array}{c}\text { Moribund patient who is not expected to survive without } \\
\text { operation }\end{array}$ \\
\hline VI & $\begin{array}{c}\text { A declared brain dead patient whose organs are being } \\
\text { removed for donor program. }\end{array}$ \\
\hline
\end{tabular}

\section{Risk factors for postponing surgery}

Grade I \& II- CCI $\geq 6$ and ASA PS $\geq 3$

Grade III - [Neurological dysfunction/Respiratory dysfunction/ jaundice (total bilirubin $>2 \mathrm{mg} / \mathrm{dl}$ ) $]+[\mathrm{CCI} \geq 4+\mathrm{ASA}-\mathrm{PS} \geq 3]$

In such situations a trial of conservative approach along with a percutaneous trans hepatic cholecystostomy should be done to tide over the acute septic crisis. This is especially suited for very sick patients suffering from acalculous cholecystitis.

This procedure should then be followed by a delayed cholecystectomy.

\section{Treatment Strategies}

The patient should be admitted to hospital. The initial treatment comprises of bowel rest, intravenous hydration, correction of electrolyte abnormalities and analgesia. Nasogastric aspiration and anti-emetics may be required in severe cases. Antibiotics have to be commenced immediately. The choice of antibiotics may be variable. These include piperacillin-tazobactam, ampicillin-sulbactam, meropenem, imipenem-cilastatin or a third generation cephalosporin combined with metronidazole ${ }^{[11,12]}$ Conservative treatment should be followed by laparoscopic cholecystectomy preferably within 72 hours [11, 12]. The conversion rate to open may be up to $30 \%$ in difficult cases. There are a few conditions wherein laparoscopic approach may be contraindicated and an open approach is preferred [13, 14] These include

1. High risk for general anaesthesia

2. Morbid obesity

3. Signs of gall bladder perforation/ peritonitis/ abscess/ fistula.

4. Large gall stones

5. Suspected carcinoma

6. End stage liver disease with portal hypertension

7. Previous abdominal surgery 
8. Septic shock with cholangitis

9. Acute pancreatitis.

Therapeutic options based on severity of acute cholecystitis. Grade I (mild). Antibiotics and supportive care followed by early laparoscopic cholecystectomy if CCI and ASA-PS scores reveal that the patient can tolerate surgery well. If patient seems to be unfit then an initial conservative approach followed by delayed surgery is a safe option ${ }^{[13]}$.

\section{Grade II (moderate)}

Supportive care and antibiotic therapy followed by surgery if CCI and ASA-PS scores suggest that the surgery would be tolerated well. Special care needs to be taken by the surgeon in order to avoid injury during surgery and a low threshold for conversion to open or a subtotal cholecystectomy should be accepted. It patient is unfit for surgery then conservative approach with biliary drainage is preferable ${ }^{[13,14,15]}$.

\section{Grade III (severe)}

Supportive care and antibiotics to be commenced on admission to hospital. Predictive factors need to be studied critically. If organ dysfunction is identified then attempts should be made to optimize function by organ support. CCI and ASA-PS scores have to be assessed. If patient can withstand then laparoscopic cholecystectomy can be performed. However chances of conversion remain high.

If patient is grossly unfit for surgery then conservative approach with early biliary drainage is advisable. This should be followed by delayed elective cholecystectomy $[14,15,16]$.

\section{Prognosis}

Uncomplicated cholecystitis has an excellent prognosis with negligible mortality. However morbidity and mortality figures rise with the severity of the disease.

\section{Conclusion}

Acute cholecystitis is a common biliary tract emergency. It requires prompt diagnosis and immediate supportive care along with antibiotics. Severity of disease decides the morbidity and mortality associated with the condition. Tokyo guidelines provide a comprehensive and lucid pattern of deciding the severity of the disease. CCI and ASA-PS assessment enables evaluation of fitness to undergo surgery. Early laparoscopic cholecystectomy is the mainstay of treatment. The chances of conversion to open are high in severe cases. Biliary drainage is an excellent salvage procedure in severe cases followed by delayed surgery.

\section{Acknowledgement}

I would like to thank Mr. Parth Vagholkar for his help in typesetting the manuscript.

\section{Conflict of interest: None \\ Funding: Nil}

\section{References}

1. Moscati RM. Cholelithiasis, cholecystitis, and pancreatitis. Emerg Med Clin North Am. 1996; 14(4):719-37.

2. Roe J. Evidence-based emergency medicine. Clinical assessment of acute cholecystitis in adults. Ann Emerg Med. 2006; 48(1):101-3.

3. Miura F, Takada T, Kawarada Y, Nimura Y, Wada K, Hirota $\mathrm{M}$ et al. Flowcharts for the diagnosis and treatment of acute cholangitis and cholecystitis: Tokyo Guidelines. J Hepatobiliary Pancreat Surg. 2007; 14:27-34.

4. Huffman JL, Schenker S. Acute acalculous cholecystitis: a review. Clin Gastroenterol Hepatol. 2010; 8(1):15-22.

5. Takada T, Strasberg SM, Solomkin JS, Pitt HA, Gomi H, Yoshida M et al. TG13: Updated Tokyo Guidelines for the management of acute cholangitis and cholecystitis. J Hepatobiliary Pancreat Sci. 2013; 20:1-7.

6. Okamoto K, Suzuki K, Takada T, Strasberg SM, Asbun HJ, Endo I et al. Tokyo Guidelines 2018: flowchart for the management of acute cholecystitis. J Hepatobiliary Pancreat Sci. 2018; 25:55-72.

7. Yokoe M, Takada T, Strasberg SM, Solomkin JS, Mayumi $\mathrm{T}$, Gomi $\mathrm{H}$ et al. New diagnostic criteria and severity assessment of acute cholecystitis in revised Tokyo Guidelines. J Hepatobiliary Pancreat Sci. 2012; 19:578-85.

8. Yokoe M, Takada T, Strasberg SM, Solomkin JS, Mayumi $\mathrm{T}$, Gomi $\mathrm{H}$ et al. TG13 diagnostic criteria and severity grading of acute cholecystitis (with videos). J Hepatobiliary Pancreat Sci. 2013; 20:35-46.

9. Yokoe M, Hata J, Takada T, Strasberg SM, Asbun HJ, Wakabayashi G et al. Tokyo Guidelines 2018: diagnostic criteria and severity grading of acute cholecystitis (with videos). J Hepatobiliary Pancreat Sci. 2018; 25:41-54.

10. Shi X, Vagholkar KR, Friess H, Uhl W, Buechler MW: Management of severe acute pancreatitis: Standards and Future Perspectives. Bombay Hospital Journal; 2001; 43:16-27.

11. Charlson ME, Pompei P, Ales KL, MacKenzie CR. A new method of classifying prognostic comorbidity in longitudinal studies: development and validation. J Chronic Dis. 1987; 40:373-83.

12. American Society of Anesthesiologists. ASA Physical Status Classification System. Available from URL: https://www.asahq. Org/resources/clinical-information/asaphysical-status-classifica tion-system.

13. Miura F, Takada T, Strasberg SM, Solomkin JS, Pitt HA, Gouma DJ et al. TG13 flowchart for the management of acute cholangitis and cholecystitis. J Hepatobiliary Pancreat Sci. 2013; 20:47-54.

14. Van Dijk AH, de Reuver PR, Tasma TN, Van Dieren S, Hugh TJ, Boermeester MA. Systematic review of antibiotic treatment for acute calculous cholecystitis. Br J Surg. 2016; 103(7):797-811.

15. Gomi H, Solomkin JS, Schlossberg D, Okamoto K, Takada T, Strasberg SM et al. Tokyo Guidelines 2018: antimicrobial therapy for acute cholangitis and cholecystitis. J Hepatobiliary Pancreat Sci. 2018; 25:3-16.

16. Jang SE, Park SW, Lee BS, Shin CM, Lee SH, Kim JW et al. Management for CBD stone-related mild to moderate acute cholangitis: urgent versus elective ERCP. Dig Dis Sci. 2013; 58:2082-7. 